\title{
A Conceptual Framework for Quality of Care
}

\author{
Ali Mohammad Mosadeghrad \\ British Institute of Technology and E-Comerce, London, United Kingdom
}

Corresponding author: Dr. Ali Mohammad Mosadeghrad (BSc, MSc, Mphil, PhD, PGDip, FCMI). Lecturer in Health Policy and Management British Institute of Technology \& E-Commerce. 252-262 Romford Road, London, E7 9HZ, United Kingdom. +44 (0)20 8552 3071. http://bite.ac.uk/. E-Mail: mosadeghrad@gmail.com or mosadeghrad@yahoo.com

\section{PROFESSIONAL PAPER}

\section{ABSTRACT}

Despite extensive research on defining and measuring health care quality, little attention has been given to different stakeholders' perspectives of high-quality health care services. The main purpose of this study was to explore the attributes of quality healthcare in the Iranian context. Exploratory in-depth individual and focus group interviews were conducted with key healthcare stakeholders including clients, providers, managers, policy makers, payers, suppliers and accreditation panel members to identify the healthcare service quality attributes and dimensions. Data analysis was carried out by content analysis, with the constant comparative method. Over 100 attributes of quality healthcare service were elicited and grouped into five categories. The dimensions were: efficacy, effectiveness, efficiency, empathy, and environment. Consequently, a comprehensive model of service quality was developed for health care context. The findings of the current study led to a conceptual framework of healthcare quality. This model leads to a better understanding of the different aspects of quality in health care and provides a better basis for defining, measuring and controlling quality of health care services.

Key words: Healthcare organisations, Quality, Pluralistic evaluation.

\section{INTRODUCTION}

Quality has become an increasingly predominant part of our lives (1-15). People are constantly looking for quality products and services. Quality healthcare is a human right. Higher healthcare quality results in satisfaction for the clients (patients and the community in general), employees, suppliers and better performance for the organisation (16-30). If quality of healthcare services improves, costs decrease, productivity increases and a better service would be available for clients, which in turn enhances organisational performance and provides long-term working relationships for employees and suppliers (31-50).

Quality, because of its subjective nature and intangible characteristics, is difficult to define. Healthcare service quality is even more difficult to define and measure than in other sectors (51-62). Distinct healthcare industry characteristics such as intangibility, heterogeneity and simultaneity make it difficult to define and measure quality (25, $35,36,38)$. The complex nature of healthcare practices, the existence of many participants with different interests in the healthcare delivery and ethical considerations add to the difficulty $(11,47,62)$.

Donabedian (9) defined healthcare quality as 'the application of medical science and technology in a manner that maximises its benefit to health without correspondingly increasing the risk'. Øvretveit (2009) defines quality care as the 'provision of care that exceeds patient expectations and achieves the highest possible clinical outcomes with the resources available' (42).

According to Schuster et al. (1998: 518), good healthcare quality means "providing patients with appropriate services in a technically competent manner, with good communication, shared decision making and cultural sensitivity". Leebov and colleagues (2003) believe that quality in healthcare means "doing the right things right and making continuous improvements, obtaining the best possible clinical outcome, satisfying all customers, retaining talented staff and maintaining sound financial performance". For Lohr (1991: 21), quality is "the degree to which healthcare services for individuals and population increases the likelihood of desired healthcare outcomes and is consistent with the current professional knowledge".

\section{LITERATURE REVIEW}

Quality healthcare is a multi-dimensional concept. Donabedian (9) distinguished three components of quality healthcare: technical quality, interpersonal quality, and amenities. Technical quality relates to the effectiveness of care in producing achievable health gain. Interpersonal quality refers to the extent of accommodation of the patient 
needs and preferences. The amenities include features such as comfort of physical surroundings and attributes of the organisation of service provision. He later proposed the triad structures, processes and outcomes as a framework for assessing quality of care. Structure refers to the attributes of the settings in which care is provided. It includes such elements as resources, staff and equipment. Process covers all aspects of delivering care and is related to interaction within and between practitioners and patients. Outcome focuses on the end result or the effect of the care provided (9.10).

$\emptyset$ vretveit (42) developed a system for improving the quality of healthcare based on three dimensions of qualityprofessional, client and management quality. Professional quality is based on professionals' views of whether professionally assessed consumer needs have been met using correct techniques and procedures. Client quality is whether or not direct beneficiaries feel they get what they want from the services. Management quality is ensuring that services are delivered in a resource-efficient way.

Joss and Kogan (25) in their model of quality, see the concept of quality in terms of three dimensions: technical, systemic and generic quality. Technical quality is concerned with the professional content of work within a given area. Systemic quality refers to the quality of systems and processes that operate across the boundaries between areas of work. Generic quality refers to those aspects of quality which involve inter-personal relationships.

Grönroos (14) distinguished two types of service quality: technical and functional quality. Technical quality refers to the delivery of the core service or outcome of the service (i.e., what is offered and received), while functional quality refers to the service delivery process, or the way in which the customer receives the service (i.e., how the service is offered and received).

Maxwell (34) identified six dimensions of quality: effectiveness, acceptability, efficiency, access, equity and relevance. Hulka and colleagues (21) used three dimensions for assessing quality healthcare: "personal relationship", "convenience" and "professional competence". Thompson (54) considered seven dimensions for evaluating healthcare service quality: "tangible", "communications", "relationships between staff and patients", "waiting time", "admission and discharge procedures", "visiting procedures" and "religious needs". Baker (3) concentrated on "consultation time", "professional care" and "depth of relationship". Tomes and $\mathrm{Ng}$ (55) used eight dimensions including "empathy", "understanding of illness", "mutual respect", "dignity", "food", "physical environment" and "religious needs".

Camilleri and O'Callaghan (5) considered seven attributes for measuring quality of hospital services: "professional and technical care", "service personalization", "price”, "environment", "patient amenities", "accessibility" and "catering". Andaleeb (1) used five dimensions for healthcare quality measurement: "communication", "cost", "facility", "competence" and "demeanour". Jun et al. (1998) using focus group interviews identified the following 11 dimensions: "tangibles", "courtesy", "reliability", "communication", "competence", "understanding customer", "access" "responsiveness", "caring", "patient outcomes" and "collaboration". Another five dimensions identified by Hasin et al. (17) are "communication", "responsiveness", "courtesy", "cost" and "cleanliness".

Walters and Jones (59) considered "security", "performance", "aesthetics", "convenience", "economy" and "reliability" for measuring hospital service quality. John (1989) found four dimensions of health care service quality: "curing", "caring", "access" and "physical environment". Jabnoun and Chaker (22) used ten dimensions for evaluating service quality of hospitals. These include: "tangibles", "accessibility", "understanding", "courtesy", "reliability", "security", "credibility", "responsiveness", "communication" and "competence".

Various health care stakeholders' perspectives and priorities must be considered in any effort to define, measure and improve quality of healthcare. While some empirical research has been carried out in this area $(6,13,20,37,41$, $45,52)$, very limited research has been conducted into the quality of service provided by Iranian healthcare organisations (Tafreshi et al., 2007). However, most of these studies were limited to perspectives of one or at the most two healthcare stakeholders.

This study aims to fill this research gap by empirically exploring the attributes of quality of health care services from the perspective of various healthcare stakeholders in Iran. It reflects on a number of aspects of quality that are unique in healthcare context and therefore affect the way that the quality of healthcare services can be measured and enhanced. This information would be useful for managers and professionals who would like to improve the performance of healthcare services. This information will also be important to consumers demanding high quality healthcare services.

\section{METHODOLOGY}

\subsection{Purpose and objectives}

This study therefore aims to provide a framework for healthcare service quality by exploring the perspectives of various healthcare stakeholders (healthcare professionals, clients, managers, payers, policy makers and accreditators) in Iran.

\subsection{Method}

Due to the complexity and multi-dimensionality of the quality of healthcare, research exploring it is methodologically difficult. There are many participants involved in the delivery of healthcare, each having his/her own interest and concern (18). Therefore, the assessment of quality cannot be carried out reliably by one stakeholder (patient or provider) alone.

Pluralistic evaluation (49) can overcome the tradition of professionally dominated healthcare evaluation by identifying and representing the views of a range of stakeholder groups, including marginalised groups and developing findings which are objective. The pluralistic approach does not rely on consensus but evaluates multiple perspectives. Hence, each stakeholder group has their views, and concerns represented in the evaluation $(15,16,49)$. Furthermore, gathering views of a range of stakeholder groups reveals the limitations of services $(15,16,19)$. 
Individual and focus group interviews were conducted with key healthcare stakeholders in Isfahan, Iran. These included clients $(n=384)$, providers $(n=266)$, managers $(n=10)$, policy makers $(n=10)$, payers $(n=10)$, suppliers $(n=10)$ and accreditation panel members $(n=10)$. Stakeholder perceptions of what constituted high quality healthcare services were elicited. Evaluation is therefore not only pluralistic (representing a range of views) but becomes situational (15), reflecting the actual status of healthcare services in Iran.

\subsection{Settings and participants}

Hospital care in Iran is provided by a network of regional hospitals located in the main cities. This includes the government financed Ministry of Health (MOH) hospitals, the Social Security Organisation affiliated (SSO) hospitals and private hospitals. The study was carried out at eight hospitals, four MOH hospitals (three teaching and one nonteaching), two SSO and two private hospitals to represent the three dominant hospital care systems in Iran.

Healthcare delivery is shaped by clients, providers, regulators, payers and suppliers. As the purpose of this study was to explore the perceptions and preferences of healthcare stakeholders about the quality of healthcare, the sampling strategy has to meet the nature of multi professional healthcare organisations dealing with many stakeholders.

A 'purposive' (Maxwell, 2004) sample of nine groups of stakeholders who were representative members of the larger population was employed in this study to adequately capture the heterogeneity in the population (Table1). In-depth faceto-face interviews were used for gathering the perspectives of outpatients, patient's relatives, doctors, managers, policy makers, accreditators, suppliers, payers, and quality managers. This study also relied on the focus group discussion method to generate qualitative data on the preferences and expectations of inpatients and providers (except doctors) for healthcare quality.

\begin{tabular}{|c|c|c|}
\hline Patients & $\begin{array}{l}32 \text { Focus group discussions with in- } \\
\text { patients (IPG) } \\
64 \text { Individual interviews with out- } \\
\text { patients (OP) }\end{array}$ & 320 \\
\hline Patients' relatives & $\begin{array}{c}64 \text { Individual interviews with patients' } \\
\text { relatives (RE) }\end{array}$ & 64 \\
\hline Providers & $\begin{array}{l}64 \text { Individual interviews with physicians } \\
\text { (MD) } \\
24 \text { Focus group discussions with other } \\
\text { providers (PRG) }\end{array}$ & 256 \\
\hline Managers & $\begin{array}{l}10 \text { Individual interviews with managers } \\
\text { (MA) }\end{array}$ & 10 \\
\hline Policy makers & $\begin{array}{c}10 \text { Individual interviews with policy } \\
\text { makers (PM) }\end{array}$ & 10 \\
\hline Suppliers & $\begin{array}{l}10 \text { Individual interviews with suppliers } \\
\text { (SU) }\end{array}$ & 10 \\
\hline Payers & $\begin{array}{l}10 \text { Individual interviews with payers } \\
\text { (PA) }\end{array}$ & 10 \\
\hline Accreditators & $\begin{array}{c}10 \text { Individual interviews with } \\
\text { accreditators }(A C)\end{array}$ & 10 \\
\hline Quality managers & $\begin{array}{l}10 \text { Individual interviews with quality } \\
\text { managers (QM) }\end{array}$ & 10 \\
\hline Total & & 700 \\
\hline
\end{tabular}

Table 1. Number of interviews and the codes
In each hospital, four focus group discussion meetings were conducted with a variety of inpatients of different genders, ages, and socio-economic status, who were admitted in the hospital for more than 2 days. Thirty two (32) focus groups were conducted with 256 inpatients (8 inpatients in each group). Groups were stratified to be homogenous based on gender. Moreover, a purposive sample of eight outpatients in each hospital was invited to participate in in-depth individual interviews (64 in all).

Inclusion criteria were: (i) ability to speak Persian; (ii) 15 years of age or older; (iii) not to be suffering from severe mental or cognitive disorders, (iv) willing to participate (v) communicable and (vi) to be well enough to participate in the interview.

In each hospital, three focus group meetings were held with employees from nursing, paramedical, and support departments who volunteered to participate. Each group included eight participants (192 in all). It was difficult to gather physicians into focus groups due to their busy time schedules. Thus, it was decided to use in depth face-to-face interviews ( 8 in each hospital, 64 in all). A purposive sample of eight patients' family members in each hospital was invited to participate in in-depth individual interviews (64 in all). Ten in depth face-to-face interviews each were held with other stakeholders including policy makers, payers, suppliers, managers, quality managers and accreditors (60 in total).

Potential participants were approached individually by the researcher, informed of the study aims and methods and invited to participate in the interview after an informed consent had been obtained. The researcher created a relaxed atmosphere and encouraged free discussion.

\subsection{Data collection}

Interviews with in-patients were conducted in a private room off the main ward. Some inpatients were interviewed in the patients' rooms due to the unavailability of the interview room. Interviews with outpatients were conducted in the outpatient department after they received services. Interviews with other healthcare stakeholders were conducted in their office or in a seminar room as focus group cases. The Interviews were recorded using a digital voice recorder with the participants' permission to facilitate analysis. Notes have been taken for those participants who were reluctant with voice recording $(2.4 \%)$.

\subsection{Data analysis}

The digital files were transcribed by the author himself. Once the files were transcribed, they were read while listening to the conversation in order to verify the accuracy of transcription. Confidentiality was assured and anonymity protected by the use of alphabetical and numerical codes on voice records and reports. The transcripts were reviewed several times to identify codes, categories and themes from the respondent's words using QSR NVivo qualitative dataanalysis software (version 7).

Codes that were found to be conceptually similar in nature or related in meaning were grouped into categories, which were then reduced and conceptualised into major themes through ongoing discussion between the researcher and debreifers (open coding). Relationships between categories and subcategories were examined and identified using 


\begin{tabular}{|c|c|c|c|c|c|c|c|c|c|c|c|}
\hline Demographic variables & IP & $\mathrm{OP}$ & RE & MD & PR & MA & PA & PM & SU & QM & $A C$ \\
\hline \multicolumn{12}{|l|}{ Gender: } \\
\hline Male & 50 & 48.4 & 45.3 & 78.1 & 35.8 & 90 & 90 & 100 & 100 & 50 & 50 \\
\hline Female & 50 & 51.6 & 54.7 & 21.9 & 64.2 & 10 & 10 & - & - & 50 & 50 \\
\hline \multicolumn{12}{|l|}{ Marital status: } \\
\hline Single & 21.4 & 10.9 & 17 & 9.5 & 12.6 & - & - & - & - & 10 & 10 \\
\hline Married & 78.6 & 89.1 & 83 & 90.5 & 87.4 & 100 & 100 & 100 & 100 & 90 & 90 \\
\hline \multicolumn{12}{|l|}{ Age: } \\
\hline Less than 20 years & 9.4 & 4.7 & 3.1 & - & - & - & - & - & - & - & - \\
\hline 20 to 29 years & 19.9 & 31.3 & 23.4 & 3.1 & 14.6 & - & - & - & - & 10 & 10 \\
\hline 30 to 39 years & 25.4 & 29.7 & 39.1 & 43.8 & 50.5 & 30 & 50 & 20 & - & 60 & 50 \\
\hline 40 to 49 years & 23.8 & 18.8 & 23.4 & 35.9 & 29.7 & 40 & 50 & 70 & 100 & 30 & 40 \\
\hline 50 years or older & 21.5 & 15.6 & 10.9 & 17.2 & 5.2 & 30 & - & 10 & - & - & - \\
\hline \multicolumn{12}{|l|}{ Education: } \\
\hline \multirow{3}{*}{$\begin{array}{c}\text { Illiterate } \\
\text { Elementary } \\
\text { Diploma }\end{array}$} & 12.5 & 3.1 & 1.6 & - & - & - & - & - & - & - & - \\
\hline & 45.7 & 43.7 & 34.3 & - & 2.1 & - & - & - & - & - & - \\
\hline & 30.0 & 31.3 & 37.5 & - & $\begin{array}{l}2.1 \\
9.9\end{array}$ & - & - & - & 40 & - & - \\
\hline Post diploma & 3.9 & 6.3 & 4.7 & - & 20.4 & - & - & - & 10 & - & - \\
\hline Bachelor of science & 6.3 & 12.5 & 18.8 & - & 63.5 & 40 & 50 & - & 40 & 50 & 50 \\
\hline \multirow{2}{*}{$\begin{array}{l}\text { Master of science } \\
\text { General Practitioner (GP) }\end{array}$} & 1.6 & - & 3.1 & - & 2.6 & 10 & 30 & 10 & - & 40 & 10 \\
\hline & - & - & - & 60.9 & 1 & 20 & 20 & 30 & 10 & 10 & 40 \\
\hline $\begin{array}{l}\text { Doctor of philosophy } \\
\text { Or Medical consultant }\end{array}$ & - & 3.1 & - & 39.1 & 0.5 & 30 & - & 60 & - & - & - \\
\hline
\end{tabular}

Table 2. The demographic characteristics of the participants

axial coding. Finally, the process of developing and refining the conceptual model occurred in selective coding (51).

\subsection{Evaluating the quality of research}

The researcher has not allowed personal values to influence the conduct of the research and findings derived from it. In this research, after data analysis, member checks (respondent validation) were done in face-to-face discussions with a subgroup of participants in order to verify and validate the findings. Member checking consisted of reporting back preliminary results to a group of participants, asking for comments on the findings and interpretations, and incorporating these critiques into the results.

The researcher also utilised peer debriefing with five quality management experts. Peer reviewers debriefed with the researcher by presenting a summary of the gathered data, categories and themes that emerged and the researcher's interpretations of the data. The peer debriefers provided the researcher an opportunity to clarify his interpretations about the nature of quality healthcare and to examine his biases.

\section{RESULTS}

\subsection{Characteristics of the participants}

Seven hundred persons participated in the interviews (Fifty-six focus group discussions and two hundred and fifty two individual interviews). Table 2 shows the main demographic characteristics of the interviewees. Fifty-one percent (358) of the participants were male. The average age of the participants was 38 years (with a range of $15-78$ years).

\subsection{Quality attributes in healthcare}

One hundred and eighty two (182) attributes of quality of healthcare were revealed by all participants. Table 3 shows those characteristics or features of healthcare services that are needed to satisfy both internal and external customers.

Healthcare service attributes identified in this study were primarily classified into tangible and intangible categories. Tangible attributes of healthcare services (Environment) refer to the physical facilities (e.g. structure, building, equipment) and personnel (quantity and quality) that create the capacity to provide healthcare services. Intangible attributes of healthcare services further divided into 4 groups: Empathy, Efficiency, Effectiveness and Efficacy. Empathy refers to the ability of understanding and caring the healthcare setting provides its customers. Interpersonal relations attributes such as effective listening, trust, respect, confidentiality, courtesy, sympathy, understanding, responsiveness, helpfulness, compassion and effective communication between providers and clients are in this group.

Efficiency refers to the extent to which resources are used well in achieving a given result. It shows the ratio of the benefits of services to the associated costs of producing those services. 'Effectiveness' and 'efficacy' of care refer to the degree to which desired results and outcomes of care are achieved. The former refers to meeting customer expectations and the latter deals with the extent to which the provider's objective of providing the service has been achieved. Figure 1 shows a model of quality dimensions in healthcare (Five E's model).

\subsubsection{Environment}

Although patients are concerned with the technical aspect of care, they mostly tend to form their opinions about service quality based on their assessment of non-clinical aspects of care such as the availability and accessibility of facilities and amenities, security in and around the facility, clean and comfortable rooms, privacy, tasty meals, comfortable clothes, and a quiet and attractive environment. Healthcare services should be available to patients any time they need them. "During my trip to Isfahan I felt so bad and came to this hospital. The doctor said it is hepatitis and that I have to stay here [hospital] for about one month. I decided to go to my city. In Abadan [patient city], the doctor said 'we do not have an ICU and in case there is a need, you must go to Ahvaz [another city]'. I decided to come back 


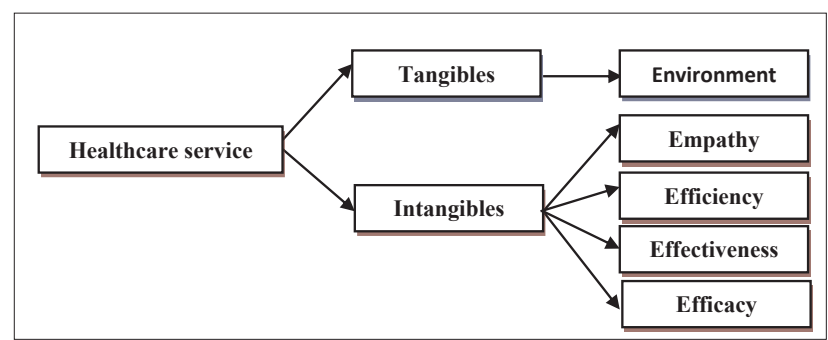

Figure 1. A model of quality measurement in healthcare

\section{to Isfahan.” (IPG11)}

Healthcare service availability is a necessity but it is not enough. Services should be accessible to clients if they are to be considered useful. Patients are concerned about having accessible doctors and nurses (Physical access) and having affordable (Financial access) and acceptable healthcare services (Conceptual access). Healthcare services should be physically accessible to clients, "Since the day I was admitted [three days ago], the doctor visited me just today morning." (IPG1) "Although the doctor was competent, I am dissatisfied. One night my face was swollen. The nurse called him, but he did not turn up." (OP10) Patients expect to have timely access to healthcare services: "The waiting time is too long. I was given an appointment for an MRI in 40 days." (OP20) "I was told to bring my child 3 months later for physiotherapy." (OP37)

Affordability is a key access component especially when service costs are high and the patient has no insurance programme. If a patient cannot afford to visit a doctor or pay for necessary clinical tests, then there is inadequate access to healthcare. "I'm suffering from a blood disorder and have to come regularly to this hospital. It is difficult for me to afford the costs." (OP59) "The medicines are very expensive. I can- not afford them." (IPG31) Healthcare services should also be acceptable and meet client wishes, desires and expectations: "I feel comfortable with a woman doctor. I feel more relaxed to talk about my disease to her." (OP19) "The doctor does not care about my religious beliefs. In the operation theatre, while I was suffering from the pain, I prayed and asked the Imam for help. He [doctor] said if he could help, he would help himself." (IPG7)

The healthcare service environment was acknowledged as an important healthcare quality component. Clients preferred a clean and homelike environment: "The room is well decorated. It is more beautiful than my own bedroom. It is coloured light pink-very beautiful." (IPG5) The physical cleanliness and hygiene considerations due to their links to hospital acquired infections were mentioned by most clients as important quality attributes: "The ward is not clean enough." (IPG4) "This is the worst hospital I have ever seen. It is very dirty. Bed sheets and pillows are dirty." (RE7) The way that the cleaning staff carried out their work was also scrutinised by clients. "They [cleaners] do not consider hygiene principles. For example, they clean the room with the same cloth and mop they use to clean the bathroom and toilet." (IPG4) Patients expected professionalism from staff and felt anxious regarding their care if certain standards were not met.

Although a hospital is a place for treating diseases, there is always a chance of getting contaminated with diseases. Contamination fears make clients worry during their hospital stay. A clean hospital assures patients that they are safe. Participants concurred that ensuring patient safety is an essential factor in the delivery of care. "I am suffering from a kind of cancer. During chemotherapy, my body will be very weak and I can contract any disease quickly. I am so

\begin{tabular}{|c|c|c|c|c|c|}
\hline $\begin{array}{c}\text { Acceptability } \\
\text { Accessibility } \\
\text { Accountability } \\
\text { Accreditability } \\
\text { Accuracy } \\
\text { Ability } \\
\text { Adaptability } \\
\text { Adaptively Adequacy } \\
\text { Advisability Aesthetics } \\
\text { Affordability Amenities } \\
\text { Appearance } \\
\text { Applicability Appreciably } \\
\text { Approachability } \\
\text { Appropriateness } \\
\text { Assurance } \\
\text { Attentiveness } \\
\text { Attitude } \\
\text { Attractiveness } \\
\text { Authenticity Authority } \\
\text { Autonomy Availability } \\
\text { Awareness } \\
\text { Balance } \\
\text { Beauty } \\
\text { Benevolence } \\
\text { Brightness }\end{array}$ & $\begin{array}{c}\text { Capacity } \\
\text { Care } \\
\text { Cheerfulness } \\
\text { Choice } \\
\text { Clarity } \\
\text { Cleanliness } \\
\text { Collaboration Colour } \\
\text { Comfort } \\
\text { Commitment } \\
\text { Communication } \\
\text { Comparability Compassion } \\
\text { Competence } \\
\text { Competitiveness } \\
\text { Completeness } \\
\text { Comprehensibility } \\
\text { Concern } \\
\text { Confidence } \\
\text { Confidentiality } \\
\text { Conformity } \\
\text { Conscientiousness } \\
\text { Consideration } \\
\text { Consistency Continuity } \\
\text { Convenience } \\
\text { Cooperation } \\
\text { Coordination } \\
\text { Correctness } \\
\text { Courtesy } \\
\text { Coverage }\end{array}$ & $\begin{array}{c}\text { Creativity } \\
\text { Credibility } \\
\text { Creditworthiness } \\
\text { Dependability } \\
\text { Durability } \\
\text { Ease } \\
\text { Education Effectiveness } \\
\text { Efficacy } \\
\text { Efficiency } \\
\text { Eligibility Empathy } \\
\text { Empowerment } \\
\text { Enthusiasm } \\
\text { Environment Friendliness } \\
\text { Equality } \\
\text { Equity } \\
\text { Ethics } \\
\text { Evidence-based } \\
\text { Excellence } \\
\text { Exclusivity Existence } \\
\text { Expertise Extensibility } \\
\text { Facilities } \\
\text { Fairness } \\
\text { Familiarity } \\
\text { Fault-free } \\
\text { Feasibility Flexibility }\end{array}$ & $\begin{array}{c}\text { Formality } \\
\text { Friendliness } \\
\text { Functionality } \\
\text { Growth Guidance } \\
\text { Health Helpfulness } \\
\text { Honesty } \\
\text { Hospitality } \\
\text { Humanity } \\
\text { Individuality } \\
\text { Informative } \\
\text { Innovativeness } \\
\text { Integrity } \\
\text { Intelligent } \\
\text { Intensity Involvement } \\
\text { Joy } \\
\text { Justice } \\
\text { Kindness } \\
\text { Legitimacy Listening } \\
\text { Love } \\
\text { Loyalty } \\
\text { Maintainability } \\
\text { Measurability } \\
\text { Motivation } \\
\text { Necessity } \\
\text { Objectivity } \\
\text { Openness Orderliness }\end{array}$ & $\begin{array}{c}\text { Passion } \\
\text { Patience } \\
\text { Patient-centeredness } \\
\text { Performance Pleasantness } \\
\text { Politeness } \\
\text { Precision } \\
\text { Predictability Presence } \\
\text { Price } \\
\text { Privacy } \\
\text { Professionalism } \\
\text { Profitability Prudence } \\
\text { Punctuality } \\
\text { Purity } \\
\text { Quiet } \\
\text { Readability } \\
\text { Reasonableness Relevance } \\
\text { Reliability } \\
\text { Repeatability Reputation } \\
\text { Respect } \\
\text { Response Responsibility } \\
\text { Responsiveness } \\
\text { Result orientation } \\
\text { Re-usability Robustness } \\
\text { Safety }\end{array}$ & $\begin{array}{c}\text { Satisfaction } \\
\text { Security Sensitivity } \\
\text { Shape } \\
\text { Size } \\
\text { Skill } \\
\text { Soundness } \\
\text { Speed } \\
\text { Stability } \\
\text { Structure } \\
\text { Suitability } \\
\text { Support } \\
\text { Sustainability } \\
\text { Sympathy } \\
\text { Timeliness } \\
\text { Tranquillity } \\
\text { Transparency } \\
\text { Trustworthy } \\
\text { Understanding } \\
\text { Uniformity } \\
\text { Uniqueness } \\
\text { Usability } \\
\text { Usefulness } \\
\text { Utilisation } \\
\text { Validity } \\
\text { Value } \\
\text { Visibility }\end{array}$ \\
\hline
\end{tabular}

Table 3. Attributes of healthcare service quality 
worried about this." (IPG29)

Other tangible quality aspects such as amenities and tasty food are also important for patients: "Hospital ' $X$ ' was better than this hospital. The clothes were disposable." (IPG30) "I cannot leave the ward, because of my disease [cancer]. There is no entertainment or TV in the ward. I get depressed and want to go home." (IPG29) "The food is great and well packed. The breakfast was butter and honey. I could not eat it. Therefore, they gave me nuts and cheese." (IPG5)

Clients feel more comfortable if providers respect their privacy during counselling sessions and examinations. Lack of privacy can make it more difficult for patients to participate actively in their treatment plan: "Although she [doctor] was kind, it was difficult for me to explain my physical problem in front of all those [medical] students. I felt really embarrassed." (OP22)

Patients desired for technically knowledgeable, skilful, and experienced providers capable of accurate diagnoses and effective treatment. Competent healthcare providers seemed to be an important quality indicator for clients: "The doctor is so important in order to have an accurate diagnosis and on time treatment." (IPG15) "Some nurses do not know how to get my blood vein for injection; they hurt me... If the hospital looks like a bunch offlowers [very clean and tidy], but there are no competent doctors and nurses, it is absolutely useless." (IPG7)

Tangibles and amenities affect patient confidence in other aspects of the service. "Here [private hospital] it is very clean. When one sees this cleanliness, one can trust them on the other aspects of care." (IPG5) This statement shows that due to the patient's lack of knowledge about technical aspects of care, she generalised her perception of the tangible aspects of care to intangible aspects. Patients use proxy attributes such as cleanliness, and security to judge the overall quality of healthcare services.

\subsubsection{Empathy}

Participants also defined quality as interaction between patients and providers. Many patients and their relatives rely on interpersonal relations attributes such as effective listening, trust, respect, confidentiality, courtesy, sympathy, understanding, responsiveness, helpfulness, compassion and effective communication between providers and clients to evaluate healthcare quality because they lack sufficient technical knowledge.

Clients wanted providers not only to do their technical jobs but also to be caring, polite, courteous and friendly, to show respect, empathy, sensitivity and kindness, and to express compassion and sympathy for the patient. "A nurse just thinks that s/he has to install a serum or get a blood sample. There is no good attitude here. (IPG11) "I wish they [providers] were more kind. I am their guest for a while. I will die soon because of my disease's [cancer] progress. I would like to be treated with respect." (IPG29)

Responsiveness was a strong concern for clients. Having supportive and caring staff responsive to individual needs was viewed as essential to providing quality hospital care. Patients expect their caregivers to be more responsible and accountable and provide prompt service: "I did not have a serum or medicine last night, but the nurses came to see me regularly to make sure I was OK." (IPG9) "Last night I felt very bad. The nurses did not give me a painkiller. My daughter brought some for me from home." (IPG1) Patients expect healthcare services to be provided within an appropriate interval: "I did the X-Ray four days ago. However, I did not get the result in order to show it to the doctor. It makes the process of treatment so long." (IPG4) "The nurse does not administer the medicines on time." (IPG24) "When the serum is finished it takes 5-6 hours to be replaced." (IPG20)

Showing emotional support seemed to contribute to service quality. It was important for patients to get emotional support from providers to help reduce their vulnerability and anxiety: "I'm suffering from cancer. I do not know what is going on. I do not know whether I will be cured or not. I am completely disappointed. I need someone to talk to me and give me support." (IPG29) "A patient has no spirit and morale and feels like a prisoner here [hospital]. It would be nice if for once a nurse would come and ask you how you are doing." (IPG9); "Nurses are great. They are like angels. They talk to me nicely. The first night I did not feel good, they came to my room every half hour. Their extreme kindness gives me tranquillity." (IPG5)

Patients expected staff to acknowledge and treat them as individuals, and show an interest in providing good quality care: "The doctor does not spend enough time with the patient. I said my belly is aching and he prescribed [clinicall tests. It did not take more than a minute." (OP45) "The doctor does not bother himself to stand up and examine the patient' throat. He just prescribes the medicine while sitting on the chair. At least he should see if the patient has fever or check the patient's blood pressure." (IPG21)

Patients were more interested in the quality of communication and information flow. "I think communication is an important factor, which helps me to trust in providers, ask my questions and feel free to talk about my [medical] problem." (IPG15) Quality of communication includes listening carefully and attentively and providing clinical status and care processes information. Patients expect healthcare providers to tell them all the facts related to their treatment process, so that they can make an informed choice based on their particular needs and preferences: "The nurse just told me 'Go and lie on bed No.11'. She did not give me information about my disease and treatment process. The nurse did not tell me why the doctor prescribed these medicines for me." (IPG29) "At the time of discharge, nobody told me when I should return to remove the stitches or for how long I would have to take the antibiotics." (IPG16)

Patients expect doctors and nurses to clearly explain technical information in an understandable way: "I saw a physician explaining the treatment procedure to an old man by using professional words. He [patient] does not understand it and will forget it. The physician should explain it to the patient's relatives." (PRG2) "I am from another city. Our culture and language are different. I may not understand their [caregivers] questions. They get angry if I ask them to repeat the question." (IPG12) "I did not understand what the doctor said. He just said something and left [the ward]. I do not know whether he is going to do the operation in this hospital or in another one. I have to ask the nurses." (RE20)

Patients' satisfaction with information transmission varies because of their educational level and the severity of 
disease. Clients with a higher level of education may want detailed information about treatment, risks, and side effects. "Nurses are great. They answer my questions." (IP2, female, 50 years old, illiterate); "I expect them to keep me fully informed, tell me everything about my disease, and explain everything." (IP14, female, 34 years old, BSc) In the case of a severe disease, patients are very keen to know all about their disease and their chance for recovery: "I have cancer. I expect them [doctors and nurses] to tell me everything about my disease and the chance of being cured." (IPG29)

Although providers are aware of the effect of interpersonal relations on patient satisfaction, there are factors affecting their personal attitude and behaviour. Lack of training and workload are among them: "Two factors affect nurses" interpersonal attitudes: workload and education level. Too much work makes employees tired and impatient. Training can help them improve their interpersonal skills." (PRG7)

Patient involvement in the decisions about their care is another quality facet. A participant argued, "Patient involvement in the treatment processes help us to know what they really need and how we can provide it effectively." (QM2) Clients expect to be more actively engaged in treatment decisions. "The doctor does not let me ask my questions. Then, at home I think, if I had asked this question it would have been better." (IPG29) Patients are more likely to be involved when they are encouraged to be active. "A doctor should ask a patient questions about his/her age, income level, [medical] problem, diet, etc. A patient may not know what to say. When the doctor asks, the patient has to answer." (OP48); "The doctor must ask questions like what is your problem? Where is it hurting? and let you explain your problem." (OP33)

Although providers recognised patient's rights to be involved in the treatment process, they distinguished between involvement and what they call intervention: "It is a patient's right to be involved in the treatment process. However, some patients mistook it [involvement] with intervention. It is acceptable if a patient asks me to prescribe a tablet form of a medicine instead of its injection form. However, some patients ask me to prescribe a specific medicine. This is not involvement. It is intervention in the treatment process." (MD6)

\subsubsection{Efficiency}

Efficiency is the best possible use of available resources to achieve maximum results. Efficiency is related to avoiding the wastage of resources in delivery services. Wasteful or deficient care means lower quality healthcare services. "Healthcare services should be provided in a way that maximise the benefits through the utilisation of the resources." (MA8); "Providing the right [Healthcare] service at the right time with the lowest resource wastage satisfies both service provider and receiver." (PM1); "Providing the best services through using available resources which satisfied both customer and provider." (MD1) and "Achieving the best outcomes using the least resources." (MD20)

\subsubsection{Effectiveness}

Effectiveness refers to the intermediate and short-term clinical and non-clinical outcomes. Effective services mean that diagnosis, care, treatment or intervention achieves the desired outcomes from the patient perspective. Patient satisfaction is an important attribute of healthcare services from this perspective. Patient satisfaction was considered an important service quality indicator by different participants (e.g., patients, their relatives, managers, policy makers and payers): "Patient satisfaction is very important for us." (MD11); "We do our best to satisfy patients." (MA1); "Quality should involve customer satisfaction." (PRG3); "Achieving patient satisfaction is our first goal" (PRG5) and "Quality means patient satisfaction." (PM3)

Healthcare services should also be comprehensive, coordinated and reliable to be considered effective from a client perspective. Clients also should be involved in the process of healthcare provision. Care provision should cover all aspects of disease management- from prevention to rehabilitation. Patients also perceive a need for more comprehensive care, such as counselling and having access to scarce medicines: "I am here [hospital] for my foot problem [broken leg]. Sometimes I feel no sensation in my hand. I asked a consultant to have a look at it. He gave me his business card and asked me to see him in his [private practice] office. I expect doctors to help me with my other problems as well." (IPG15) "The hospital does not provide some of the medicines that the doctor prescribed. I had to find them outside of the hospital." (IPG23)

Patients expected coordination between individuals and organisations involved in their care, such as multiple providers within a hospital, between doctors and other clinical staff across facilities and between their providers and their medical insurance plans: "The doctor asked for a laboratory test, but nobody [nurses] came to do the test. I had to go to the laboratory department with my daughter." (IPG30)

Reliability of services is another important attribute of quality healthcare. Clients expect providers to perform the promised service dependably and accurately. "This is the third time I am going to do this [clinical] test. The first time the test showed hyperthyroidism. The second time it showed hypothyroidism. Therefore, the doctor asked me to do it again but in this hospital."(OP6) "The opening time in the obstetrics clinic is 7.30 AM. The time is now $8.00 \mathrm{AM}$ but nobody is there." (OP22)

\subsubsection{Efficacy}

Efficacy refers to the final and long-term clinical outcomes such as patient well being and quality of life. Efficacious services mean that diagnosis, care, treatment or intervention achieves the desired or projected clinical outcomes from the provider perspective. Professionals (e.g., physicians) mainly believed that patient satisfaction could not be considered a good quality indicator, at least regarding technical services. Physicians argue that patients lack the clinical expertise to judge the quality of the technical aspects of healthcare services they receive: "Our job is professional [technical] and the patient does not know many things about it. S/he does not know what is actually going on in the operation theatre." (PM1)

They provided specific examples of patients' lack of knowledge of the technical aspects of healthcare services: "If I remove the normal appendicitis of patients with bellyache symptoms and discharge them quickly, I will have a lot of patients [patients will be satisfied]." (MD44) "The patient does not know the differences between using Halothane and Isoflurane in the operation theatre." (MD29) "It is defined in the medical profession that a neuroplasty surgery recovers $50 \%$ of the abilities of the nerve. A patient might expect 
$100 \%$ recovery and may not be satisfied. It is not possible technically."(MD43) "Some of our work like injection is aggressive. Patient might not like it." (PRG22)

They believe that a patient can be satisfied with care that is not high quality and can be dissatisfied with quality care. "It is difficult to define quality in healthcare. A patient might die even when high quality services are provided. For example, a CVA [Cerebro Vascular Accident, stroke, or brain attack $]$ patient might die even when competent staff may have provided services using the best equipment. in contrast, a patient with a cold might recover, even if the quality of service was low." (MD17) "A penicillin injection might be the best way to get the best outcome for a child. However, the patient might resist. S/he will not be satisfied with it."(MD44)

Physicians also emphasised the probability of achieving desired clinical outcomes: "A 50 year old patient cannot expect to have all the abilities of a 30 year old person after a cosmetic surgery. His or her appearance might look like a young person. However, s/he will not have the abilities of a 30 year old person." (MD28); "A doctor cannot guarantee the $100 \%$ success of an operation on a pancreatic cancer patient." (MD8)

They considered clinical indicators as the most important indicator of quality: "The final clinical outcome is important for me. Was the CPR [Cardio Pulmonary Resuscitation] successful? Could I resuscitate the dying patient?” (MD2) "For me, the final accepted clinical outcome is important, not patient satisfaction." (MD11)

\section{DISCUSSION}

In professional healthcare services, quality is a subjective, complex and multi-dimensional concept. The study identified more than 100 attributes of quality of healthcare which are in some respects similar to those identified by other studies on healthcare quality $(9,12,20,24,27,40,46,58,60)$.

Generally, healthcare quality definition in this study include characteristics such as availability, accessibility, acceptability, appropriateness, affordability, technical competence, timeliness, privacy, confidentiality, empathy, attentiveness, caring, responsiveness, accountability, accuracy, reliability, comprehensiveness, continuity, equity, environment, amenities and facilities. Other attributes used to describe quality healthcare include educational provision for the patient and family about patient health issues and including the patient and family in treatment planning processes. Efficacy, effectiveness, efficiency, ensuring safety and security, reducing mortality and morbidity, improving quality of life and patient's health status, and patient satisfaction have also been seen as quality attributes.

Therefore, quality healthcare is consistently delighting a patient by providing efficacious, effective and efficient healthcare services according to the latest clinical guidelines and standards, which meet the patient needs and satisfy providers. As a result, healthcare services should have the capacity to meet the expectations of both the patient and the healthcare provider.

Quality healthcare can also be defined as: "Providing the right healthcare services in a right way in the right place at the right time by the right provider to the right individual for the right price to get the right results". Eight Quality "Rights" are included in this definition of healthcare service quality. They include the 'Right Care', in a 'Right Way' for the 'Right Individual', in the 'Right Place', at the 'Right Time', by the 'Right Person', and for the 'Right Price' to achieve the 'Right Results'. The definition helps create a common language for the quality planning, measurement and improvement throughout the healthcare system.

Measurable attributes of quality can be used as a framework to measure and improve the quality of healthcare services. For instance, SERVQUAL has been used increasingly in health sector $(2,7,8,29,50,61)$. Parasuraman et al. (1985) identified ten determinants of services quality including reliability, responsiveness, competence, access, courtesy, communication, credibility, security, understanding and tangibles. These ten service quality determinants were condensed later into five dimensions: reliability, responsiveness, tangibles, assurance and empathy and a measure including 22 items called SERVEQUAL was developed (44).

Parasuraman et al. (44) defined service quality as the differences between perception (customers' judgement of the service they received) and expectations (what they feel the service should be). Therefore, service quality can be modelled as:

$\mathbf{S Q}=\sum\left(\mathbf{P}_{\mathrm{ij}}-\mathbf{E}_{\mathrm{ij}}\right)$

SQ $=$ Service Quality

$\mathrm{k}=$ Number of attributes

$\mathrm{Pij}=$ Performance perception of stimulus i with respect to attribute $j$

Eij $=$ Service quality expectation for attribute $j$ that is the relevant norm for stimulus i

However, SERVQUAL dimensions of quality cannot be generalised to all service industries. Some studies found that SERVQUAL did not cover all the aspects of healthcare service quality that were important to healthcare stakeholders $(4,30,32,46,53,56)$. Additional attributes of quality such as 'accessibility', 'affordability', 'caring', and 'medical outcomes' should be added, representing more specific healthcare quality aspects.

The identified attributes of quality healthcare in this study were grouped into five dimensions: efficacy, effectiveness, efficiency, environment and empathy (5Es). The fiveEs model provides a more comprehensive view of quality. It uses a combination of different indicators and measures to assess the structure, context, processes and outcomes of health care services quality to make sure those attributes of healthcare quality identified in this study are met. While 'Effectiveness' refers to meeting customer expectations, 'Efficacy' deals with the extent to which the provider's objective of providing the service has been achieved. Patients might think that a treatment was effective and feel satisfied by receiving just a simple service (e.g., relieving pain with a painkiller). However, providers may not achieve their objectives (i.e., disease treatment). Efficiency of healthcare services is also an important dimension of quality, which affects the utilisation of resources for providers, and service affordability for customers. The quality of environment (e.g., amenities) and empathy (e.g., interpersonal relationships) are also important because of their impact on outcomes of 


\begin{tabular}{|c|c|c|c|c|c|}
\hline $\begin{array}{c}\text { Quality attributes } \\
\text { Key participant }\end{array}$ & Efficacy & Effectiveness & Efficiency & Empathy & Environment \\
\hline Care giver & +++++ & ++++ & + & ++ & +++ \\
\hline Patient & ++++ & +++++ & + & +++ & ++ \\
\hline Manager & ++++ & +++++ & +++ & + & ++ \\
\hline Payer & ++++ & +++++ & +++ & + & ++ \\
\hline Policy maker & ++++ & +++++ & +++ & + & ++ \\
\hline
\end{tabular}

Table 4. The importance of quality attributes for healthcare stakeholders

care. For example, in a clean and comfortable hospital, a good interpersonal relationship between the patient and the healthcare provider is more likely to be established. This leads to a potentially more complete and accurate diagnosis and treatment and patient compliance with the treatment process.

The findings from this qualitative study seem to be consistent with other research, which found various healthcare stakeholders have different perceptions of important attributes of quality healthcare (Grimmer, et al., 1999 and Kerssens et al., 2004). Stakeholder groups prioritised efficacy, effectiveness, efficiency, empathy and environment differently and as a result defined the quality of healthcare service differently (Table 4).

Patients view effectiveness, empathy and environment as important dimensions of quality healthcare. Clients place more emphasis on effective services, ready access to experienced and helpful providers, clean and safe environment, and facilities and amenities. Interpersonal and environmental factors affect mostly client satisfaction. For them, the most important attributes of quality healthcare are having their medical problem resolved, having skilled, competent, supportive and caring providers who are concerned about them, listen to them, protect their privacy, involve them and their families in the decisions about their treatment, and give them equal care. Patients' relatives consider costeffectiveness important. Healthcare providers should meet these clients' values and expectations to satisfy them.

Healthcare professionals regard efficacy of treatment as more important than the other dimensions. For them healthcare quality refers to service aspects that bring satisfaction to them-having the best possible outcomes and meeting clinical guideline requirements. Patient satisfaction was considered less important by the healthcare professionals (e.g., Medical doctors). This finding is consistent with the previous studies (39).

Effectiveness and efficiency are of primary importance to managers, policy makers and payers. Managers often emphasised client satisfaction and resource utilisation, whereas payers considered customer satisfaction as the most important indicator. Policy makers tend to feel that access, cost, equity and effectiveness are the most important attributes of quality.

Therefore, service quality can be modelled as:

$\mathbf{S Q}=\sum \mathbf{I}\left(\mathbf{P}_{\mathrm{ij}}-\mathbf{E}_{\mathrm{ij}}\right)$

$\mathrm{SQ}=$ Service Quality

$\mathrm{k}=$ Number of attributes

I= Importance of quality attributes

$\mathrm{Pij}=$ Performance perception of stimulus $\mathrm{i}$ with respect to attribute $j$

Eij $=$ Service quality expectation for attribute $j$ that is the relevant norm for stimulus i

\section{CONCLUSION AND IMPLICATIONS FOR POLICY MAKERS}

The pluralistic evaluation in this study revealed a comprehensive picture of quality of healthcare services in a way that would not have been possible had a singular evaluation approach been used.

The pluralistic approach of the evaluation revealed that quality healthcare service has different meanings for clients, healthcare providers, managers, policy makers and payers. Those healthcare quality dimensions that are important to every group involved in the provision of healthcare services should be a priority for managers and practitioners. If they want to satisfy their clients, they need to perform well on these dimensions. These dimensions provide input for developing a model of quality management.

In conclusion, this study has added to our understanding of quality healthcare, highlighting its complex nature. The study has direct implications for healthcare service providers. They are encouraged to regularly monitor healthcare quality and accordingly initiate continuous quality improvement programmes to maintain high levels of patient satisfaction. The findings can be used in the development of an instrument to measure quality of healthcare services. The findings have important implications for policy makers. Their support, in terms of providing necessary resources and establishing supportive rules and regulations is critical.

\section{LIMITATIONS AND IMPLICATIONS FOR FURTHER RESEARCH}

Qualitative methods allowed the author to explore the perspectives of healthcare stakeholders including patients, their family, healthcare providers, third-party payers, managers, policy makers and accreditors about quality healthcare. The in-depth interviews and focus groups were useful in developing survey questionnaires for measuring healthcare stakeholders' perspectives about quality of healthcare. Subsequently, quantitative surveys were used to measure the frequency and distribution of these ideas.

However, several aspects of this research limit the robustness of its findings. First, a small number of policy makers, managers and payers was chosen for interviewing. A much larger sample might have given somewhat different results. Second, respondents were healthcare organisation stakeholders in Iran and the results of the study cannot 
be generalised to other countries or healthcare systems. Third, as in any study of this type, selection bias among participants may pose problems when drawing conclusions from the data.

\section{REFERENCES}

1. Andaleeb SS. Determinants of customer satisfaction with hospitals: a managerial model. International Journal of Health Care Quality Assurance. 2003; 6(11): 181-187.

2. Anderson EA. Measuring service quality at a university health clinic. International Journal of Health Care Quality Assurance. 1995; 2(8): 32-37.

3. Baker R. Development of a questionnaire to assess patients' satisfaction with consultations in general practice. British Journal of General Practice. 1990; 40(341): 487-490.

4. Bowers MR, Swan JE, Koehler WF. What attributes determine quality and satisfaction with health care delivery? Health Care Management Review. 1990; 9(4): 49-55.

5. Camilleri D, O'Callaghan M. Comparing public and private hospital care service quality. International Journal of Health Care Quality Assurance. 1998; 4(11): 127-133.

6. Conley H, Kubsch SM, Ladwig J, Torres C. Patients' and Nurses, perceptions of quality nursing activities. British Journal of Nursing. 2003; 12(19): 1122 -1129.

7. Curry A, Sinclair E. Assessing the quality of physiotherapy services using SERVQUAL. International Journal of Health Care Quality Assurance. 2002;15(5): 197-205.

8. Dean A. The applicability of SERVQUAL in different healthcare environments. Health Marketing Quarterly. 1999; 16 (3): 1-21.

9. Donabedian A. The definition of quality and approaches to its assessment. Ann Arbor: Michigan Health Administration Press. 1980.

10. Donabedian A. The quality of care: How can it be assessed? Journal of the American Medical Association. 1988; 260 (12): 1743-1748.

11. Eiriz V, Figueiredo JA. Quality evaluation in healthcare services based on customer-provider relationships. International Journal of Health Care Quality Assurance. 2005; 18 (6-7): 404-412.

12. Evans D B, Edejer T T, Lauer J, Frenk J, Murray C J L. Measuring quality: From the system to the provider. International Journal for Quality in Health Care. 2001; 13: 439-446.

13. Grimmer, K, Sheppard L, Pitt M, Magarey M, Trott P. Differences in stakeholder expectations in the outcome of physiotherapy management of acute low back pain. International Journal for Quality in Health Care. 1999; 11: 155-162.

14. Grönroos C. A service quality model and its marketing implications. European Journal of Marketing. 1982; 18(4): 36-44

15. Hall JE. Pluralistic evaluation: A situational approach to service evaluation. Journal of Nursing Management. 2004; 1(12): 22-27.

16. Hart E. The use of pluralistic evaluation to explore people's experiences of stroke services in the community. Health and Social Care in the Community. 1999; 7(4): 248-256.

17. Hasin MAA, Seeluangsawat R, Shareef MA. Statistical measures of customer satisfaction for health-care quality assurance: a case study. International Journal of Health Care Quality Assurance. 2001; 14(1): 6-14.

18. Hassan, D. Measuring performance in the healthcare field:
A multiple stakeholders' perspective . Total Quality Management \& Business Excellence. 2005; 16 (8-9): 945-953.

19. Heyman B. Researching user perspectives on community healthcare. Chapman and Hall. 1995.

20. Hudelson P, Cléopas A, Kolly V, Chopard P et al. What is quality and how is it achieved? Practitioners' views versus quality models. Quality and Safety in Health Care. 2008. 17(1): 31-36.

21. Hulka BS, Zyzanski SJ, Cassel JC, Thompson SJ. Scale for the measurement of satisfaction with medical care: modifications in content, format and scoring. Medical Care, 1970; 12: 611.

22. Jabnoun N, Chaker M. Comparing the quality of private and public hospitals. 2003.

23. John J. Quality in health care service consumption: what are the structural dimensions. In: Hawes JM, Thanopoulos J. Eds. Developments in Marketing Science. Orlando, FL: Academy of Marketing Science; 1989. 518-521.

24. Johnston R. The determinants of service quality: Satisfiers and dissatisfies. International Journal of Service Industry Management. 1995; 6(5): 53-71.

25. Joss R, Kogan M. Advancing quality: Total quality management in the National Health Service. Buckingham: Open university press; 1995

26. Peterson JM, Zsidisin GA. The identification and measurement of quality dimensions in health care: Focus group interview results. Health Care Management Review. 1998; 23(4): 81-96.

27. Kelly DL. Applying quality management in healthcare: A process from improvement. Health Administration Press.; 2003.

28. Kerssens JJ, Groenewegen P P, Sixma H J, Boerma WW, van der Eijk I. Comparison of patient evaluations of health care quality in relation to WHO measures of achievement in 12 European countries. Bulletin of the World Health Organization. 2004; 82(2): 106-115.

29. Kilbourne WE, Duffy JA, Duffy M, Giarchi G. The applicability of SERVQUAL in cross-national measurements of healthcare quality. Journal of Services Marketing. 2004; 18 (7): 524-533.

30. Lam SS. SERVQUAL: A tool for measuring patients' opinions of hospital service quality in Hong Kong, Total Quality Management. 1997; 8(4): 145-152.

31. Lee PM, Khong P, Ghista DN. Impact of deficient healthcare service quality. The TQM Magazine. 2006; 18(6): 563-571.

32. Lim PC, Tang NKH. A study of patients' expectations and satisfaction in Singapore hospitals. International Journal of Health Care Quality Assurance. 2003; 13(7): 290-299.

33. Maxwell JA. Qualitative research design: An interactive approach. 2nd Ed. Sage; 2004.

34. Maxwell RJ. rospectus in NHS management: quality assessments in health", British Medical Journal. 1984; 288: 148-72.

35. McLaughlin CP, Kaluzny AD. Continuous quality improvement in health care. 3rd Ed. Jones \& Bartlett Publishers. model" International Journal of Health Care Quality Assurance. 2006. 11(6): 181-187.

36. Mosadeghrad AM. Principles of healthcare management, Tehran: Dibagran Tehran, 2003.

37. Muntlin A, Gunningberg L, Carlsson M. Patients' perceptions of quality of care at an emergency department and identification of areas for quality improvement. Journal of 
Clinical Nursing. 2006;_15(8): 1045-1056.

38. Naveh E, Stern Z. How quality improvement programmes can affect general hospital performance. International Journal of Health Care Quality Assurance. 2005; 18(4): 249-270.

39. Newman K, Pyne T. Quality matters: junior doctors' perceptions. Journal of Management in Medicine. 1996; 10 (4): 12-23.

40. OBrien JL, Hughes EF. The Physician's role in Quality Assessment and Improvement. Topics in Health Care Financing; 1991; 18(2): 33-45.

41. Oermann MH. Consumers' descriptions of quality health care. Journal of Nursing Care Quality. 1999: 14(1): 47-55.

42. Øvretveit J. Health service quality: An introduction to quality methods for health services. Oxford: Blackwell. 1992.

43. Parasuraman A, Zeithaml VA, Berry LL. A conceptual model of service quality and its implications for future research. Journal of Marketing. 1985; 49: 41-50.

44. Parasuraman A, Zeithaml VA, Berry LL. SERVQUAL: A multiple-item scale for measuring customer perceptions of service quality. Journal of Retailing. 1988; 64(1): 12-40.

45. Radwin, L. Oncology patients' perceptions of quality nursing care. Research in Nursing \& Health. 2000; 23(3): 179-90.

46. Ramsaran-Fowdar RR. Identifying Health Care Quality Attributes. Journal of Health and Human Services Administration. 2005; 27(4): 428-443.

47. Rohlin M, Schaub RM, Holbrook P, Leibur E, et al. Continuous quality improvement. European Journal of Dental Education. 2002; 6(3): 67-77.

48. Schuster MA, McGlynn EA, Brook RH. How good is the quality of health care in the United States? The Milbank Quarterly. 1998. 76(4): 517-564.

49. Smith G, Cantley C. Assessing health care: A study in organisational evaluation. Milton Keynes, Open University Press; 1985.

50. Snoj B, Mumel,D. The measurement of perceived differences in service quality: The case of health spas in Slovenia, Journal of Vacation Marketing. 2002; 8(4): 362-379.

51. Strauss A, Corbin J. Basics of qualitative research: Techniques and procedures for developing grounded theory. 2nd ed. Newbury Park, CA: Sage. 1998.

52. Tafreshi MZ, Pazargadi M, Abed Saeedi Z. Nurses' perspectives on quality of nursing care: A qualitative study in Iran. International Journal of Healthcare Quality Assurance. 2007; 20(4): 320-328.

53. Taylor SA, Cronin JJ. Modelling patient satisfaction and service quality. Journal of Health Care Marketing. 1994; 14 (1): 34-44.

54. Thompson AGH. The measurement of patients' perceptions of the quality of hospital care. Unpublished doctoral thesis, UMIST, University of Manchester, Manchester, 1983.

55. Tomes A, Ng SCP. Service quality in hospital care: the development of in-patient questionnaire. International of Health Care Quality Assurance. 1995; 8(3): 25-33.

56. Tucker JL, Adams SR. Incorporating patients' assessments of satisfaction and quality: An integrative model of patients' evaluations of their care. Managing Service Quality. 2001; 11(4): 272-287.

57. Van der Bij JD, Vollmar T, Weggeman MC. Quality systems in health care: A situational approach. International Journal of Health Care Quality Assurance. 1998; 11(2): 65-70.

58. Wallace TR, Miller C, Frisch S. Perceptions of care and services by the clients and families: A personal experience. Journal of Advanced Nursing. 1999; 29(5): 1144-1153.

59. Walters D, Jones P. Value and value chains in health-care: a quality management perspective. The TQM Magazine. 2001; 13(5): 319-35.

60. Wilde B, Starrin B, Larsson G, Larsson M. Quality of care from a patient's perspective: a grounded theory study. Scandinavian Journal of Caring Sciences. 1993; 7(2): 113-120.

61. Wisniewski $\mathrm{M}$, Wisniewski $\mathrm{H}$. Measuring service quality in a hospital colposcopy clinic. International Journal of Health Care Quality Assurance. 2005; 18(2-3): 217-229.

62. Zabada CP, Rivers A, Munchus G. Obstacles to the application of total quality management in health care organisations. Total Quality Management. 1998; 9(1): 57-66. 